\title{
Особенности оптических характеристик пористого кремния и их модификация с использованием химической обработки поверхности
}

\author{
(C) А.C. Леньшин \\ Воронежский государственный университет, \\ 394000 Воронеж, Россия \\ E-mail: lenshin@phys.vsu.ru
}

(Получена 9 январа 2017 г. Принята к печати 19 апреля 2017 г.)

\begin{abstract}
Методами инфракрасной и фотолюминесцентной спектроскопии проведены сравнительные исследования особенностей состава и оптических свойств пористого кремния различной морфологии. На основе полученных экспериментальных данных и общепринятых теоретических моделей показаны основные факторы, негативно влияющие на интенсивность фотолюминесценции пористого кремния и ее деградацию под действием направленного излучения в видимом диапазоне. На примере пористого кремния с размерами пор 50-100 нм показана возможность улучшения указанных характеристик химической обработкой в полиакриловой кислоте.
\end{abstract}

DOI: $10.21883 /$ FTP.2018.03.45619.8462

\section{1. Введение}

В настоящее время для решения прикладных задач в областях современной электроники, альтернативной энергетики, медицины интенсивно ведутся исследования наноструктур на основе различных полупроводниковых материалов и соединений. В то же время технологии на многокомпонентных полупроводниковых гетероструктуpax зачастую до́роги и сложны в производстве. Поэтому ведутся активные попытки их замещения более доступными и технологичными материалами или элементами схемы на основе различных видов нанокремния: аморфного, поликристаллического, пористого и др. [1-4]. Однако наноструктуры на основе кремния ввиду своей развитой, покрытой различными водородными и гидроксильными комплексами поверхности имеют ряд проблем с деградацией состава и свойств, проявляющихся как в ходе стандартных технологических операций, связанных с нагревом, адсорбцией паров различных веществ, направленными воздействиями, так и в процессе старения в естественных условиях [5-7]. Поэтому поиск эффективных методов обработки поверхности и, по возможности, недорогих технологичных защитных покрытий для стабилизации состава и свойств наноструктур на основе кремния является актуальной научной задачей. В зависимости от области применения кремниевых наноструктур используется нанесение различных металлических или полимерных пленок (отражающих и полупрозрачных), корпусирование в вакуумную оболочку и др. Также актуальна химическая обработка поверхностей различными органическими и неорганическими соединениями и кислотами $[8,9]$. При этом, по данным ряда исследований [9-11], обработка в полиакриловой кислоте $\left(\mathrm{C}_{2} \mathrm{H}_{3} \mathrm{COOH}\right)_{n}$ (ПАК) хорошо себя зарекомендовала как метод модификации и пассивации поверхности кремниевых наноструктур.

Цель данной работы заключалась в исследовании влияния химической обработки пористого кремния в растворе полиакриловой кислоты на его люминесцентные свойства в естественных условиях и при длительном направленном возбуждающем излучении.

\section{2. Методика}

Образцы пористого кремния (por-Si) с различным размером пор получены методом электрохимического травления в растворах плавиковой кислоты на пластинах монокристаллического кремния как $n$-, так и $p$-типа. Параметры получения образцов представлены в таблице. Подробно методика получения всех образцов, особенности их морфологии по данным микроскопии, изменение состава и фотолюминесценции (ФЛ) с течением времени описаны в работе [7].

Морфология поверхности образцов пористого кремния была исследована методом растровой электронной микроскопии (РЭМ) на приборе JEOL-JSM 6380LV (рис. 1).

Наиболее интенсивную ФЛ проявили образцы пористого кремния с выраженной полосой ИК-спектра $\mathrm{Si}-\mathrm{Si}$ $\left(616 \mathrm{~cm}^{-1}\right)$, появляющейся вследствие значительного количества люминесцирующих нанокристаллов/кластеров кремния в пористом слое [6,7]. С течением времени происходит окисление образцов, это проявляется как заметное снижение относительной интенсивности указанной выше полосы и особенностей спектра, характерных для различных видов связей $\mathrm{Si}-\mathrm{H}_{x}$ $\left(664,2120-2250 \mathrm{~cm}^{-1}\right)$, и ростом интенсивности полосы $\mathrm{Si}-\mathrm{O}-\mathrm{Si}\left(1050-1200 \mathrm{~cm}^{-1}\right)$. При этом со временем интенсивность фотолюминесценции сильнее снижается у образцов, более подверженных естественному окислению [7].

Для обработки в растворе ПАК были выбраны образцы пористого кремния, аналогичные образцу 3, как обладающие наиболее яркой ФЛ из всех образцов спустя 1 месяц после их получения. Образцы пористого 

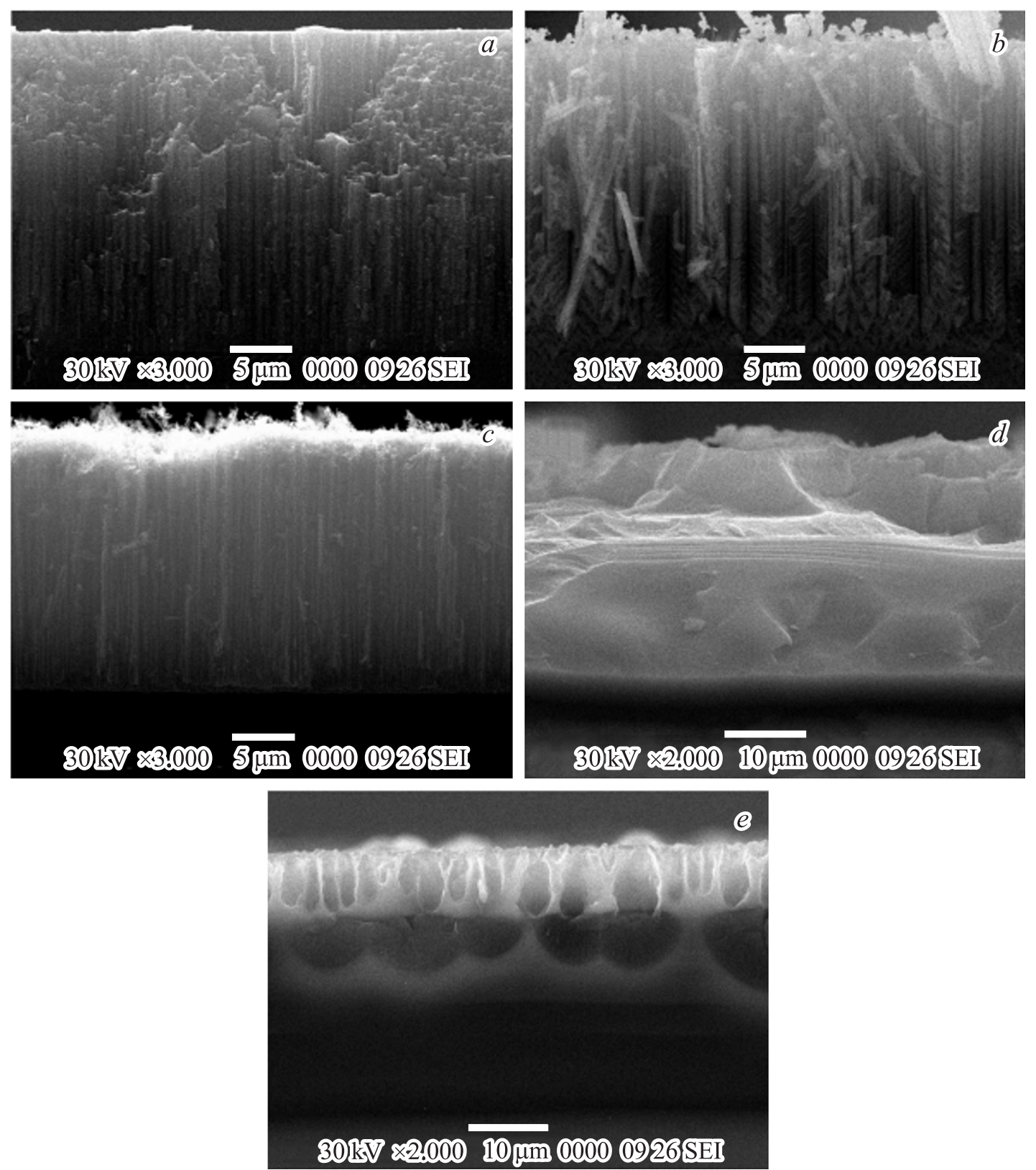

Рис. 1. РЭМ-изображения сколов образцов пористого кремния [7]: $a-$ образец $3, b-7, c-18, d-29, e-30$.
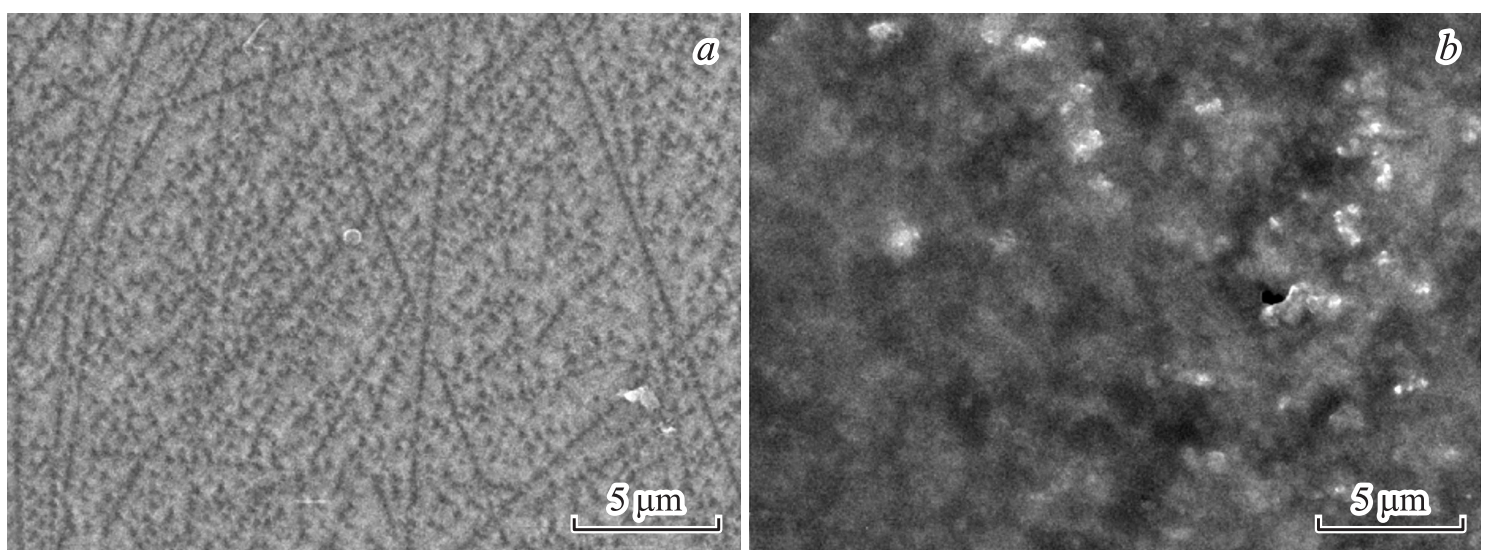

Рис. 2. РЭМ-изображения поверхности пористого кремния (образец 3$)$ до (a) и после $(b)$ обработки в ПАК. 
Режимы получения и характеристики исследуемых образцов por-Si

\begin{tabular}{|c|c|c|c|c|}
\hline $\begin{array}{c}\text { Маркировка } \\
\text { образца }\end{array}$ & $\begin{array}{c}\text { Исходная пластина, } \\
\text { удельное сопротивление } \rho, \\
\text { Ом · см }\end{array}$ & Состав травителя & $\begin{array}{c}\text { Плотность } \\
\text { тока и время } \\
\text { травления }\end{array}$ & $\begin{array}{c}\text { Размер пор } \\
\text { по данным РЭМ, нм }\end{array}$ \\
\hline 3 & КЭФ (100), 0.3 & $\mathrm{HF}: \mathrm{C}_{3} \mathrm{H}_{7} \mathrm{OH}: \mathrm{H}_{2} \mathrm{O}_{2}$ & $\begin{array}{c}15 \mathrm{Mин} \\
\sim 30 \mathrm{MA} / \mathrm{cm}^{2}\end{array}$ & $50-100$ \\
\hline 7 & КЭФ (111), 1.0 & $\mathrm{HF}: \mathrm{C}_{3} \mathrm{H}_{7} \mathrm{OH}: \mathrm{H}_{2} \mathrm{O}_{2}$ & $\begin{array}{c}15 \mathrm{Mин} \\
\sim 30 \mathrm{MA} / \mathrm{cm}^{2}\end{array}$ & $50-100$ \\
\hline 18 & КЭФ (100), 0.3 & ДМФА : $\mathrm{HF}: \mathrm{H}_{2} \mathrm{O}_{2}$ & $\begin{array}{c}15 \mathrm{мин} \\
\sim 30 \mathrm{MA} / \mathrm{cm}^{2}\end{array}$ & $150-200$ \\
\hline 29 & КЭФ (111), 10 & $\mathrm{HF}: \mathrm{C}_{3} \mathrm{H}_{7} \mathrm{OH}: \mathrm{H}_{2} \mathrm{O}_{2}$ & $\begin{array}{c}15 \mathrm{мин} \\
\sim 50 \mathrm{MA} / \mathrm{cm}^{2}\end{array}$ & Менее 10 \\
\hline 30 & $\begin{array}{l}\text { Многослойный КДБ (111)p-n } \\
\text { a) } p \text {-слой: } 0.4 \\
\text { б) } n \text {-слой: КЭФ (111), } 10\end{array}$ & $\mathrm{HF}: \mathrm{C}_{3} \mathrm{H}_{7} \mathrm{OH}: \mathrm{H}_{2} \mathrm{O}_{2}$ & $\begin{array}{c}25 \mathrm{мин} \\
\sim 30 \mathrm{MA} / \mathrm{cm}^{2}\end{array}$ & $\begin{array}{l}\text { a) } p \text {-слой } \sim 1000-2000 \\
\text { б) } n \text {-слой под } p \text {-слоем - поры } \\
\text { различного диаметра: } \\
\text { мелкие - меньше } 30 \text { нм } \\
\text { крупные - до } 2000 \text { нм. }\end{array}$ \\
\hline
\end{tabular}

кремния после получения и промывки в изопропиловом спирте погружались в водный раствор полиакриловой кислоты на 20 мин, соотношение воды и кислоты составляло $4: 1$. По данным РЭМ, обработка в ПАК (рис. 2) приводит к существенному изменению рельефа поверхности, при этом отдельные поры становятся менее выражены.

ИК-спектры пропускания образцов пористого кремния были получены на ИК фурье-спектрометре Vertex70 (Bruker) с использованием приставки для спектроскопии нарушенного полного внутреннего отражения (НПВО). Глубина исследования с помощью данной методики образцов пористого кремния в диапазоне волновых чисел до $2000 \mathrm{~cm}^{-1}$ не превышает 1.5 мкм, а в диапазоне 2000-4000 $\mathrm{cm}^{-1}$ не превышает 10 мкм. Таким образом, мы получаем данные о химических связях непосредственно в пределах пористого слоя [12,13].

Спектры фотолюминесценции регистрировались волоконно-оптическим спектрометром USB4000-VIS-NIR (Ocean Optics), сопряженным с компьютером. В качестве источника возбуждения фотолюминесценции использовался лазерный диод, излучающий на длине волны 405 нм. Плотность мощности излучения не превышала $20 \mathrm{MB} / \mathrm{cm}^{2}$. Временно́е разрешение устройства определялось разрешением спектрометра и составляло величину 3.8 мс. Для вырезания длинноволновой области излучения лазерных диодов, а также для выделения излучения люминесценции использовались соответствующие интерференционные светофильтры (ThorLabs). Площадь облучения объектов исследования и, следовательно, исследуемая область определялись площадью сечения волновода. В работе использовано кварцевое оптоволокно диаметром 600 мкм (QP600, Ocean Optics), в результате площадь зондирования составляла величи-

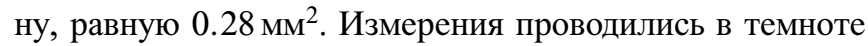
в отсутствии источников рассеянного света при комнатной температуре. От каждого образца было снято не менее десяти спектров фотолюминесценции, которые затем были усреднены [14].

Схема эксперимента для исследования кинетики деградации ФЛ была следующей: конец волновода с помощью позиционеров подводился в контакт с образцом, при этом лазерное излучение перекрывалось заслонкой и на образец не попадало. После этого открывали заслонку и детектировали сигнал фотолюминесценции на определенной длине волны, соответствующей максимуму спектра, или же в определенном интервале длин волн в зависимости от формы спектра и решаемых задач. В результате для ряда образцов была зафиксирована кинетика деградации фотолюминесценции с временны́м разрешением 3.8 мс.

\section{3. Результаты и обсуждение}

Кинетики деградации фотолюминесценции образцов пористого кремния были получены под воздействием непрерывного лазерного излучения 405 нм. Интенсивность ФЛ измерялась на длине волны максимума ФЛ образцов $\sim 650$ нм (рис. 3 ).

Графики зависимости деградации ФЛ пористого кремния с различным размером пор (от 1-3 до $200 \mathrm{Hм}$ ), а также для por-Si, в котором присутствуют макро- и микропоры одновременно под действием непрерывного лазерного излучения, полученые спустя месяц и 4 месяца после изготовления образцов, в значительной степени имеют сходство с представленными в работах [15-18]. Таким образом мы можем назвать эти зависимости характерными для данного материала. 

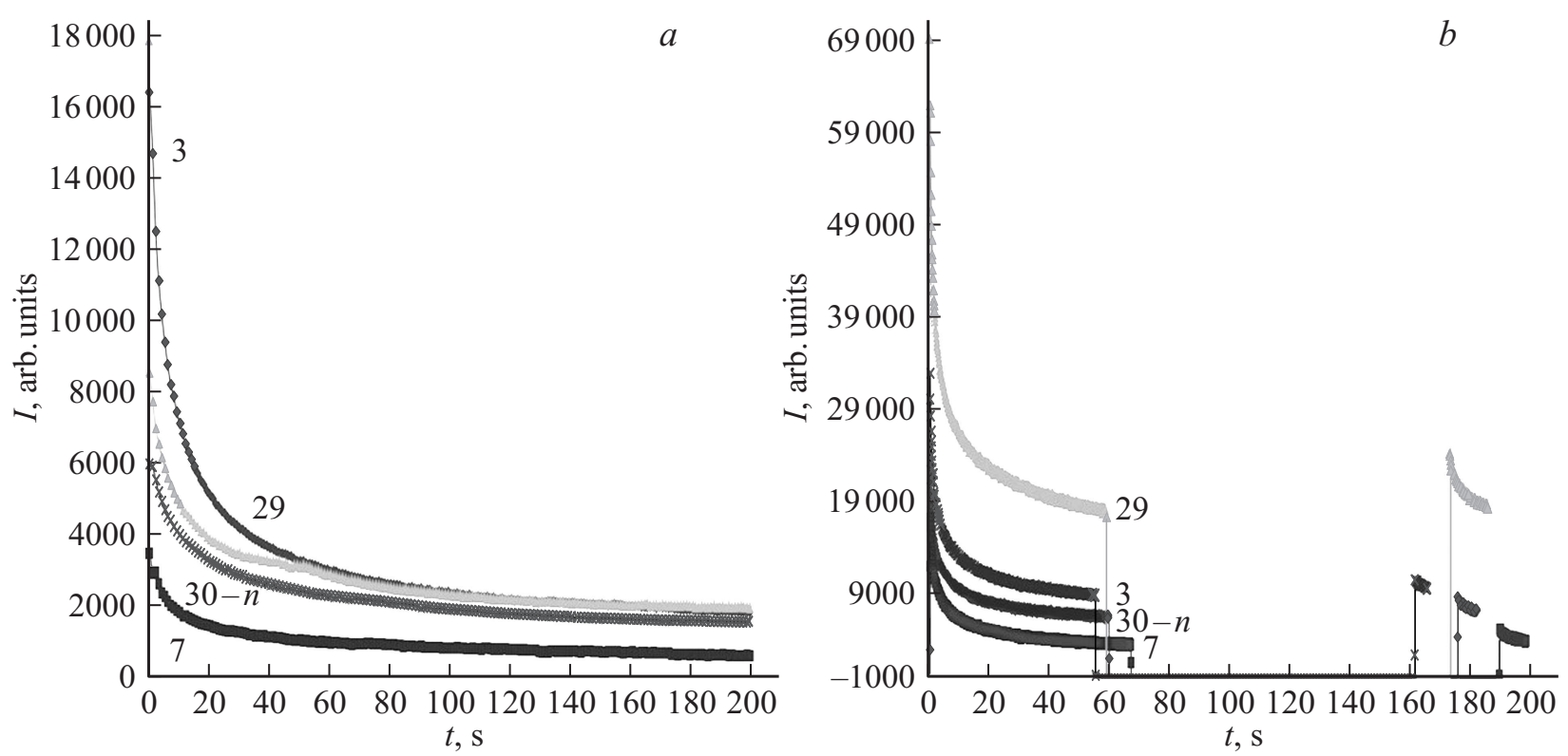

Рис. 3. Кинетики деградации ФЛ образцов пористого кремния с различным размером пор после выдержки на атмосфере: 30 ( $a$ ) и $120(b)$ дней. $\lambda=405$ нм.

Как правило, на графиках кинетики деградации ФЛ, используя аппроксимацию, выделяют две-три области, соответствующие различным физико-химическим процессам в поверхностном слое пористого кремния [15-18]. При этом скорость и степень затухания ФЛ для разных образцов может различаться. На первом участке от 0 до 15-20 с после начала возбуждения наблюдается резкий спад ФЛ. Исходя из общих представлений о природе ФЛ por-Si, подтверждаемых теоретическими расчетами [5,15-18], данный спад ФЛ связан с разрывом $\mathrm{Si}-\mathrm{H}_{x}$ связей (в некоторых случаях к ним авторы добавляют и $\mathrm{Si}-\mathrm{OH}-$ связи) под действием непрерывного лазерного излучения с выходом адсорбированного водорода и образованием центров безызлучательной рекомбинации (БР). При этом после выключения возбуждающего источника эти центры со временем восстанавливаются (рис. 4,b), по нашему мнению, вследствие повторного осаждения водорода из атмосферы.

Второй участок графика кинетики деградации ФЛ (рис. 3, a, с 20-25 с и далее) соответствует такому стабильному состоянию поверхности пористого кремния, при котором под действием непрерывного возбуждающего излучения основная часть процесса десорбции слабо связанного с поверхностью водорода уже завершилась и количество центров безызлучательной рекомбинации существенно не меняется. На этом участке графика кинетики деградации интенсивность ФЛ пористого кремния остается в целом постоянной. При этом в начале второго участка может наблюдаться плавное снижение ФЛ, которое некоторые авторы выделяют отдельно и связывают с появлением под действием возбуждающего излучения дополнительных центров БР за счет удаления с поверхности различных видов загрязнения, углеводородных связей и т.п. Кроме того, при достаточно длительном эксперименте на недавно полученных образцах может наблюдаться и некоторое повышение ФЛ за счет активного окисления поверхности „свежеполученного“ пористого кремния с аннигиляцией части центров БР, связанных с оборванными связями и дефектным оксидом [15-18].

Таким образом, поскольку поверхность пористого кремния с различным размером пор и типом проводимости зачастую существенно восприимчива к направленному воздействию внешнего источника излучения, актуальна задача поиска способа устранения данной особенности материала. Ранее было установлено, что обработка пористого кремния в растворах полиакриловой кислоты приводит к существенным изменениям состава поверхности и способствует сохранению интенсивности его ФЛ [9-11]. В связи с этим были проведены исследования влияния обработки образцов в ПАК на кинетику деградации ФЛ пористого кремния, полученного по стандартной методике (образец 3), спустя 1 и 6 месяцев после изготовления образцов.

На рис. 4 представлены ИК-спектры пропускания пористого кремния и пористого кремния, обработанного в водном растворе полиакриловой кислоты, спустя месяц (рис. 4, $a$ ) и через 6 месяцев (рис. 4,b) после изготовления образцов.

На спектре обработанного ПАК пористого кремния (рис. 4,a) появляется ряд особенностей, характерных для химических связей полиакриловой кислоты, таких как: $\mathrm{C}=\mathrm{O}-$ связи $-1707 \mathrm{~cm}^{-1}$ [10], $\mathrm{C}-\mathrm{H}_{x}$ и $\mathrm{C}-\mathrm{CH}, \mathrm{CH}-\mathrm{CH}_{3}$ в областях 1100-1250 и $1370-1450 \mathrm{~cm}^{-1}$ соответственно, $\mathrm{CH}_{2-}$ и $\mathrm{CH}_{3}$-связи в 

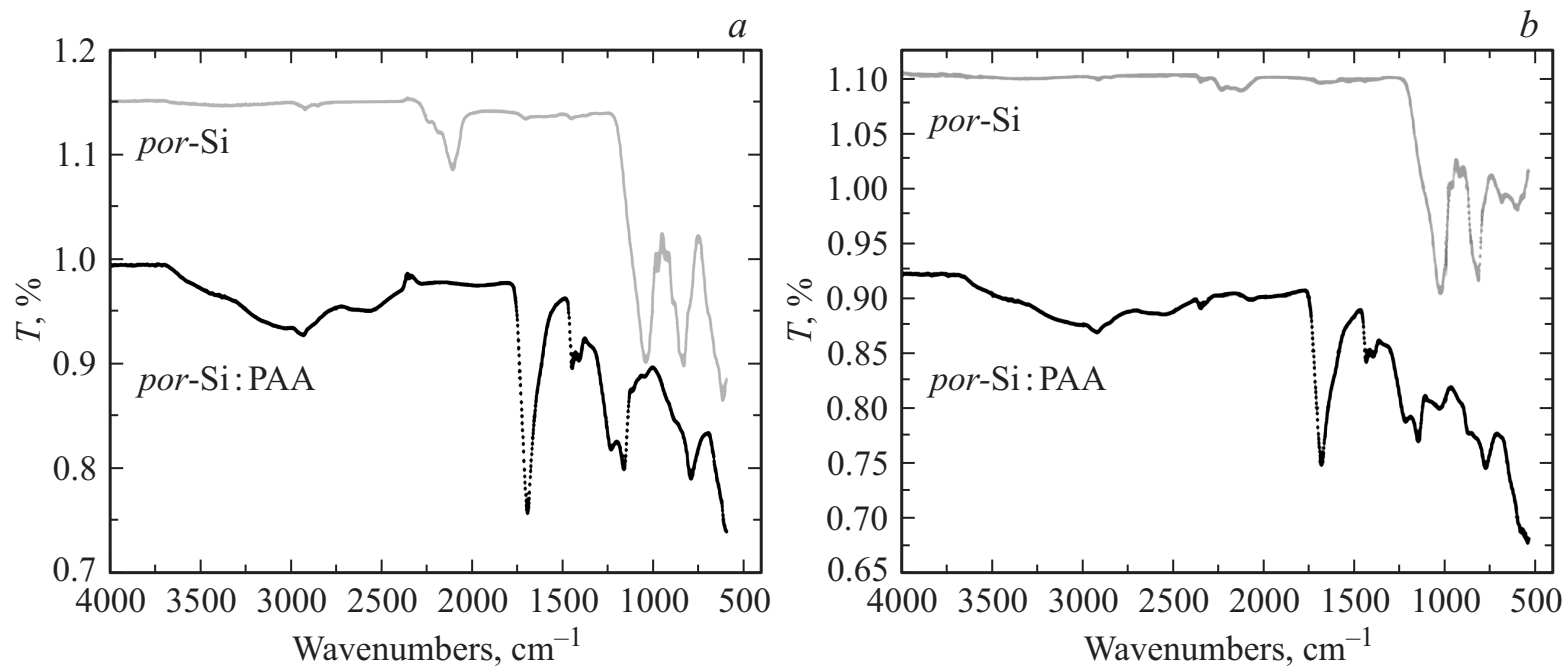

Рис. 4. ИК-спектры пропускания исходного por-Si и por-Si, обработанного в водном растворе ПАК (в течение 20 мин), через 1 (a) и 6 месяцев $(b)$ после изготовления образцов.

области 2920-2980 $\mathrm{cm}^{-1}$. Кроме того, появляются дополнительные колебания с частотой 1163 и $1238 \mathrm{~cm}^{-1}$, соответствующие связям $\mathrm{C}-\mathrm{O}$ и $\mathrm{C}-\mathrm{OH}$ полиакриловой кислоты.

Также на спектре обработанных образцов наблюдается существенное уменьшение интенсивности особенностей в области $1050-1200 \mathrm{~cm}^{-1}$, соответствующих связям $\mathrm{Si}-\mathrm{O}-\mathrm{Si}$, и в областях 2100-2250 и $\sim 800 \mathrm{~cm}^{-1}$, характерных для различных видов колебаний связей $\mathrm{Si}-\mathrm{H}_{x}$, при увеличении интенсивности полосы от связей $\mathrm{Si}-\mathrm{Si}, \mathrm{Si}-\mathrm{H}\left(600-660 \mathrm{~cm}^{-1}\right)$ по сравнению с необработанными образцами. Также по сравнению с исходным пористым кремнием наблюдается некоторое перераспределение интенсивности между пиками $\mathrm{Si}-\mathrm{H}, \mathrm{Si}-\mathrm{H}_{x}$, $\mathrm{O}_{3} \mathrm{SiH}$ в полосе поглощения $843-906 \mathrm{~cm}^{-1}$. В целом на обработанных образцах наблюдается больше особенностей, характерных для ОН-групп (3000-3500 см $\left.{ }^{-1}\right)$ [10].

Следует отметить, что в спектре образца, обработанного в полиакриловой кислоте, наблюдаются также слабые полосы 1260 и $1450 \mathrm{~cm}^{-1}$, которые могут быть обусловлены образованием некоторого количества связей $\mathrm{Si}-\mathrm{C}(\mathrm{Si}-\mathrm{CH}-\mathrm{COOH})$ в пористом слое $[9,10]$.

По прошествии 6 месяцев (рис. $4, b$ ) для исходного пористого кремния наблюдается подробно описанное в работе [7] окисление при уменьшении интенсивности полос, соответствующих $\mathrm{Si}-\mathrm{Si}$ и $\mathrm{Si}-\mathrm{H}_{x}$-связям. При этом у обработанных в растворе ПАК образцов со временем сильных изменений в спектре не происходит, соотношения интенсивностей основных полос поглощения остаются примерно теми же, несколько снижается интенсивность полосы $\mathrm{C}=\mathrm{O}$. Таким образом, по данным ИК-спектроскопии, обработка в полиакриловой кислоте приводит к уменьшению доли $\mathrm{Si}-\mathrm{H}_{x}-$ и $\mathrm{Si}-\mathrm{O}-\mathrm{Si}-$ связей на поверхности образца и стабилизирует (в течение периода исследований 1-6 месяцев) состав поверхности пористого кремния.
На рис. 5 представлены кинетики деградации образцов исходного образца пористого кремния (образец 3) и пористого кремния, обработанного в ПАК, также спустя месяц и полгода после их изготовления, снятые при возбуждении источником с длиной волны 405 нм.

После обработки в ПАК вид кривой кинетики деградации ФЛ образца пористого кремния заметно меняется. Резкое снижение интенсивности ФЛ, характерное для пористого кремния в первые несколько десятков секунд возбуждения, сопровождающее процесс выхода водорода с поверхности образцов, не наблюдается (рис. 5,a). На начальном временно́м участке зависимости, по времени большем, чем участок резкого падения ФЛ исходного пористого кремния, происходит рост интенсивности ФЛ, видимо, связанный с заполнением (релаксацией) под внешним воздействием центров безызлучательной рекомбинации непосредственно в пленке ПАК и на поверхности por-Si, при значительно меньшем количестве кремний-водородных и оборванных связей. Похожие кинетики деградации ФЛ пористого кремния с возрастанием интенсивности ФЛ на начальном участке встречались ранее в литературе на пористом кремнии, подверженном обработке в азотной кислоте [18].

На более позднем этапе съемки (2 область) кинетики деградации ФЛ обработанных в ПАК образцов наблюдается достаточно стабильная ФЛ, как и у исходного пористого кремния, но более высокая по интенсивности с небольшим ростом со временем. При временном выключении источника возбуждающего излучения и последующем включении у образцов, обработанных в ПАК, в отличие от исходных образцов, эффект, связанный c повторной адсорбцией водорода на поверхность с последующей десорбцией, практически не наблюдался (рис 5,b). У выдержанных 6 месяцев образцов описанные эффекты проявляются очень похоже, что в совокупности с данными ФЛ (рис. 6) указывает на сохранение во 

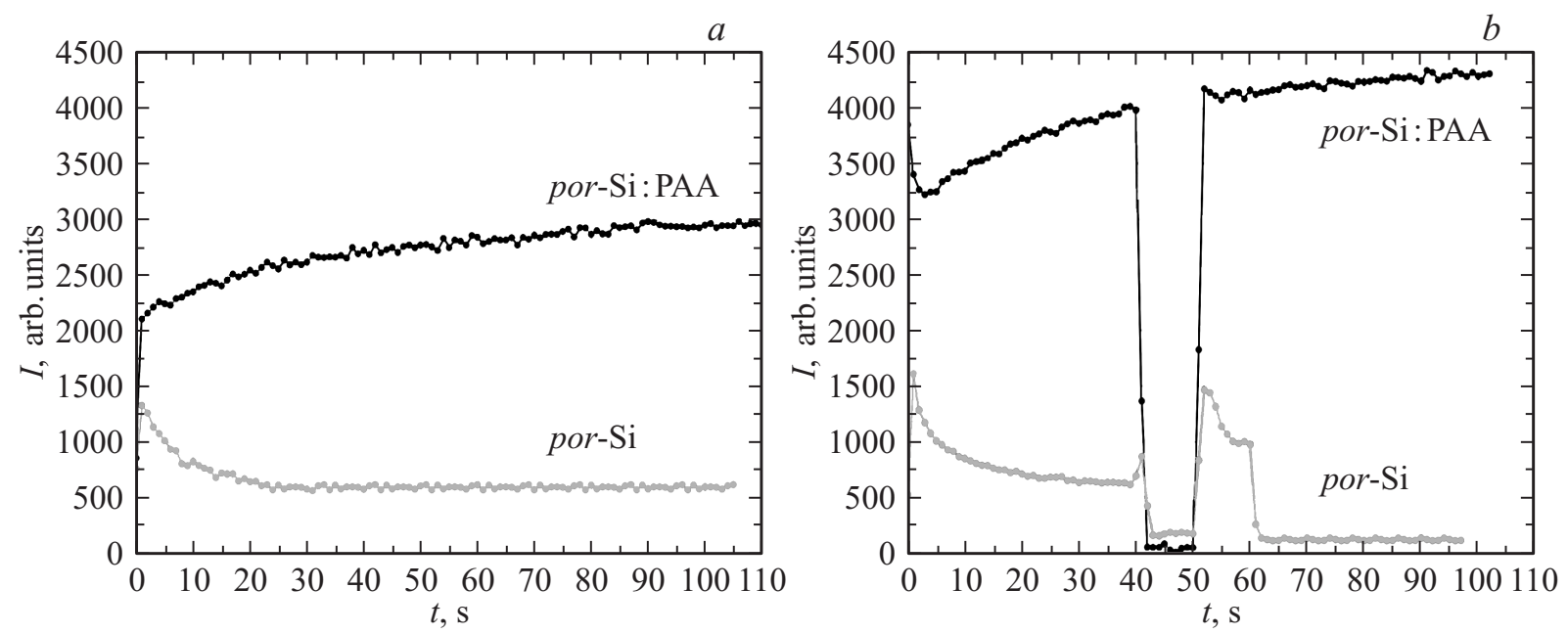

Рис. 5. Кинетика деградации ФЛ образцов пористого кремния и пористого кремния, обработанного раствором ПАК через $1(a)$ и 6 месяцев $(b)$ после изготовления. $\lambda=405$ нм.
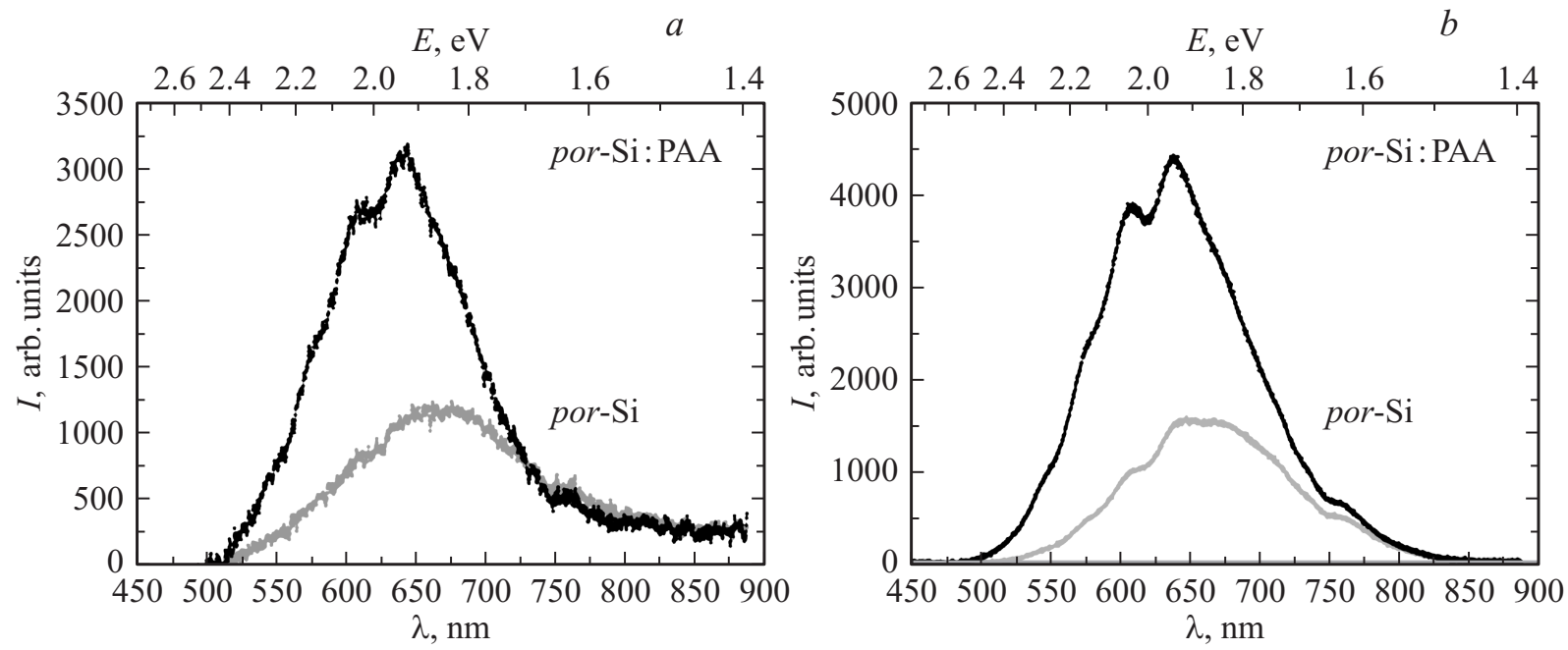

Рис. 6. Спектры ФЛ образцов пористого кремния и пористого кремния, обработанного ПАК, полученные через 1 (a) и 6 месяцев $(b)$ после изготовления.

временно́м промежутке от 1 до 6 месяцев качественного состава чувствительных к направленному воздействию излучения центров. Опыты по исследованию кинетики деградации ФЛ при возбуждении источником с длиной волны 532 нм показали аналогичные результаты.

Результаты, полученные методами ИК-спектроскопии и кинетики деградации ФЛ, хорошо согласуются с данными о фотолюминесценции образцов пористого кремния при возбуждении источником с длиной волны 405 нм (рис. 6) и данными, полученными ранее в работе [10].

Образцы por-Si после обработки в растворе полиакриловой кислоты спустя 1 и 6 месяцев после изготовления демонстрируют более высокую интенсивность фотолюминесценции ( в 3 раза). Ширина и положение полосы ФЛ после обработки ПАК не меняется, при этом происходит перераспределение интенсивности внутри полосы, по-видимому, связанное с различной степенью воздействия ПАК на разные центры безызлучательной рекомбинации, такие как дефектный оксид кремния, оборванные связи, связи $\mathrm{Si}-\mathrm{H}_{x}$, и, возможно, с возникновением дополнительных центров излучательной рекомбинации, например люминесценция связей в самой ПАК и связей $\mathrm{Si}-\mathrm{C}(\mathrm{Si}-\mathrm{CH}-\mathrm{COOH})$ на поверхности пористого кремния [9-11].

\section{4. Заключение}

В работе показано, что для пористого кремния с достаточно широким диапазоном размеров пор и различным типом проводимости характерна частичная деградация ФЛ под действием непрерывного возбуждающего излучения в видимом диапазоне, связанная с разрывом кремний-водородных связей и десорбцией водорода с 
поверхности с образованием центров безызлучательной рекомбинации. Для достижения устойчивости ФЛ пористого кремния к направленному воздействию излучения следует использовать методики, приводящие к удалению водорода с поверхности с последующей пассивацией центров БР, например, такие как химическая обработка образцов в полиакриловой кислоте. При этом следует учитывать, что наиболее интенсивную ФЛ имеют образцы пористого кремния, поверхность которых наименее окислена $[6,7]$. Полученные результаты и выводы могут способствовать более широкому применению пористого кремния в областях, связанных с фотоникой и альтернативной энергетикой.

Работа выполнена при поддержке Министерства образования и науки России в рамках государственного задания вузам в сфере научной деятельности на 2014-2016 гг. (проект № 740, задание № 3.130.2014/К) и гранта Президента РФ (МК-4865.2016.2).

\section{Список литературы}

[1] М.С. Бреслер, О.Б. Гусев, Е.И. Теруков, А. Froitzheim, W. Fuhs. ФTT, 46 (1), 18 (2004).

[2] С.Н. Шамин, В.Р. Галахов, В.И. Аксенова, А.Н. Карпов, Н.Л. Шварц, З.Ш. Яновицкая, В.А. Володин, И.В. Антонова, Т.Б. Ежевская, J. Jedrzejewski, Е. Savir, I. Balberg. ФТП, 44 (4), 550 (2010).

[3] С.К. Лазарук, А.В. Долбик, В.А. Лабунов, В.Е. Борисенко. ФТП, 41 (9), 1130 (2007).

[4] С.А. Дьяков, Е.В. Астрова, Т.S. Perova, С.Г. Тиходеев, Н.А. Гиппиус, В.Ю. Тимошенко. ЖЭТФ, 140 (1), 92 (2011).

[5] В.С. Левицкий, А.С. Леньшин, П.В. Середин, Е.И. Теруков. ФТП, 49 (11), 1540 (2015).

[6] А.С. Леньшин, В.М. Кашкаров, С.Ю. Турищев, М.С. Смирнов, Э.П. Домашевская. Письма ЖТФ, 37 (17), 1 (2011).

[7] A.S. Lenshin, P.V. Seredin, B.L. Agapov, D.A. Minakov, V.M. Kashkarov. Mater. Sci. Semicond. Processing, 30, 25 (2015).

[8] А.С. Леньшин, В.М. Кашкаров, В.Н. Ципенюк, П.В. Середин, Б.Л. Агапов, Д.А. Минаков, Э.П. Домашевская. ЖТФ, 83 (2), 136 (2013).

[9] R. Bywalez, H. Karacuba, H. Nienhaus, C. Schulz, H. Wiggers. Nanoscale Res. Lett., 7, 76 (2012).

[10] И.В. Кавецкая, В.М. Кашкаров, Д.А. Минаков, П.В. Середин, А.С. Леньшин. Поверхность. Рентгеновские, синхротронные и нейтронные исследования, 8, 89 (2015).

[11] В.М. Кашкаров, А.С. Леньшин, П.В. Середин, Б.Л. Агапов, Поверхность. Рентгеновские, синхротронные и нейтронные исследования, 9, 80 (2012).

[12] А.С. Леньшин, В.М. Кашкаров, П.В. Середин, Д.А. Минаков, Б.Л. Агапов, М.А. Кузнецова, В.А. Мошников, Э.П. Домашевская. ФТП, 46 (8), 1101 (2012).

[13] V.P. Tolstoy, I.V. Chernyshova, V.A. Skryshevsky. Handbook of infrared spectroscopy of ultrathin films (Wiley Interscience, John Wiley \& Sons, Inc., 2003).

[14] Э.К. Алгазинов, М.А. Дрюченко, Д.А. Минаков, А.А. Сирота, В.А. Шульгин. Измерительная техника, 1, 36 (2014).

[15] К.С. Журавлев, Н.П. Степина, Т.С. Шамирзаев, Э.Ю. Бучин, Н.Е. Мокроусов. ФТП, 28 (3), 482 (1994).
[16] Б.М. Костишко, А.М. Орлов, Т.Г. Емельянов. Письма ЖТФ, 22 (10), (1996).

[17] М.Е. Компан, И.Ю. Шабанов, В.И. Беклемышин, В.М. Гонтарь, И.И. Махонин. ФТП, 30 (6), 1095 (1996).

[18] Б.М. Костишко, А.М. Орлов, Т.Г. Емельянова. Письма ЖТФ, 21 (19), 32 (1995).

Редактор А.Н. Смирнов

\section{Optical characteristics of porous silicon and their modification after chemical treatment of their surface}

\section{A.S. Lenshin \\ Voroneg State University, 394000 Voroneg, Russia}

Abstract Comparative study of the composition and photoluminescence properties in porous silicon with different morphology of the porous layer was performed with the use of infrared and photoluminescence spectroscopy. Basing on the obtained experimental data and existing theoretical models the main factors having a negative effect on the intensity of photoluminescence in porous silicon and its degradation under exposure to the directed irradiation in a visible range were determined. With porous silicon where pores size was of $50-100 \mathrm{~nm}$ as an example it is shown that the above-named optical characteristics can be noticeably improved by the chemical treatment of porous silicon in polyacrylic acid. 